Millie Bobby Brown en Stranger Things.

Fuente: Bustle

VENTANA INDISCRETA | n.20 | Universidad de Lima

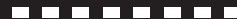




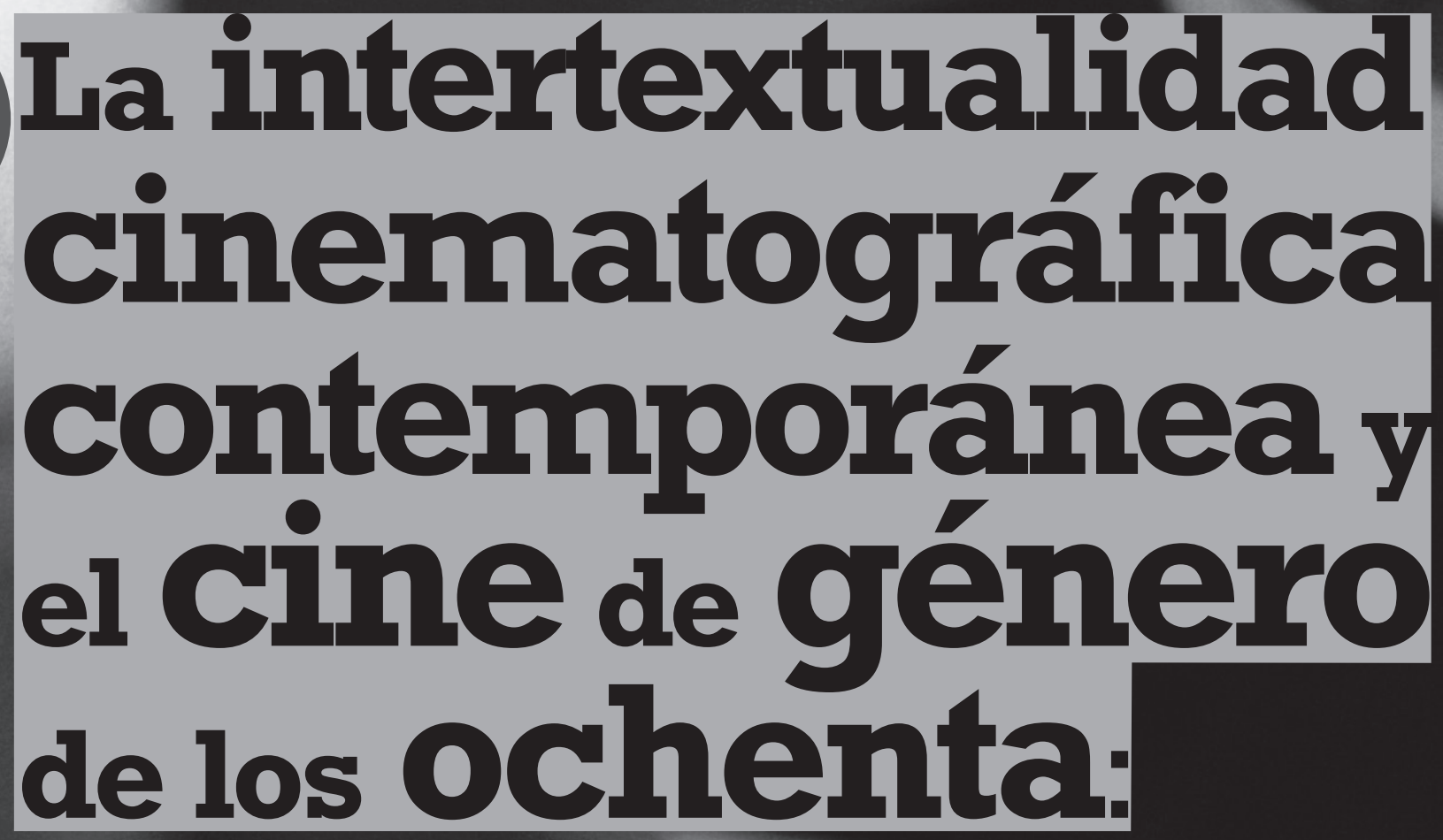

\section{el caso de}

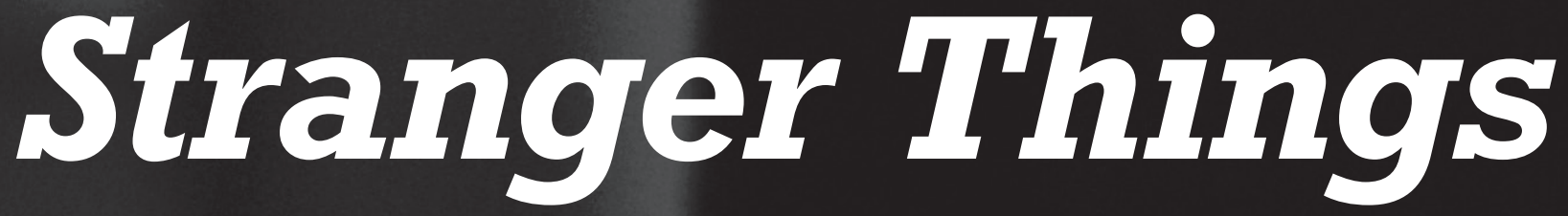

El reconocimiento de lo familiar, de lo cercano, de todo lo que invoque en nosotros memorias entrañables, se encuentra en la base de toda intertextualidad; la capacidad del espectador de identificar referencias, alusiones y homenajes puestos allí para él. Aunque no es un recurso exclusivo de nuestra época, es una tendencia cada vez más frecuente tanto en el cine como en las series de streaming, demostrando el diálogo constante en el que se encuentran ambos formatos. Veamos el caso de Stranger Things.

\section{Luis Felipe Rivera Narváez}


El nuevo milenio trajo consigo muchos cambios en la forma en que interactuamos con la información, las noticias, las personas y, en general, con las distintas esferas de la cultura. El entretenimiento audiovisual, como es el caso del cine o del actual fenómeno del streaming, no es la excepción de estos cambios producidos por el auge de las nuevas tecnologías de la comunicación. Por un lado, el cine, entendido como espectáculo comercial que se ofrece en teatros o salas, ha seguido buscando innovaciones técnicas en este siglo XXI. Un caso para mencionar sería el renovado regreso del $3 \mathrm{D}$; pensemos en Avatar (2009) de James Cameron, la más exitosa película hasta la fecha en cuestiones de recaudación y que impresionó a la industria del entretenimiento y al público con un formato que supuso un salto cualitativo en la ya conocida técnica del 3D. La propuesta de una experiencia que simula una tercera dimensión y que envuelve al espectador ayudó, en parte, a entender el gran éxito de esta película de Cameron y la posterior tendencia, muchas veces injustificada, del uso de esta tecnología ${ }^{1}$. Por otro lado, más allá de cuestiones netamente técnicas, hay que entender que el cine, al ser también un lenguaje donde la imagen tiene predominancia semántica, $\mathrm{y}$ observando también, en paralelo, las transformaciones en el consumo de contenido multimedia (YouTube, servicios de streaming y, en general, cualquier nuevo medio que escape del viejo concepto de ir al cine o ver televisión), podemos considerar que parte de este lenguaje cinematográfico y de su background temático e histórico se ha dirigido en algunos casos a los servicios de entretenimiento que se sustentan en estos nuevos soportes de exhibición.

La llegada del streaming, la tecnología que permite el acceso a un variado menú de películas, series, documentales e incluso material propio a través de la reproducción en tiempo real, no solo ha causado un impacto en la forma de distribuir y consumir entretenimiento sino también en la forma de crear contenido exclusivo para esta plataforma. El caso que nos interesa por su relevancia actual y por el tema que estamos tratando, es el servicio que brinda la empresa Netflix. Aparte de un catálogo producto de las licencias de transmisión que obtiene de proveedores asociados, ofrece una lista especial bajo el rótulo de "contenido original”, compuesta por producciones propias o por la adquisición de derechos exclusivos de transmisión ${ }^{2}$. Lo central es observar cómo actualmente ha calado con éxito en el público la idea de un producto audiovisual creado para ser consu-

Un grupo de amigos similar al de E.T. el extraterrestre.

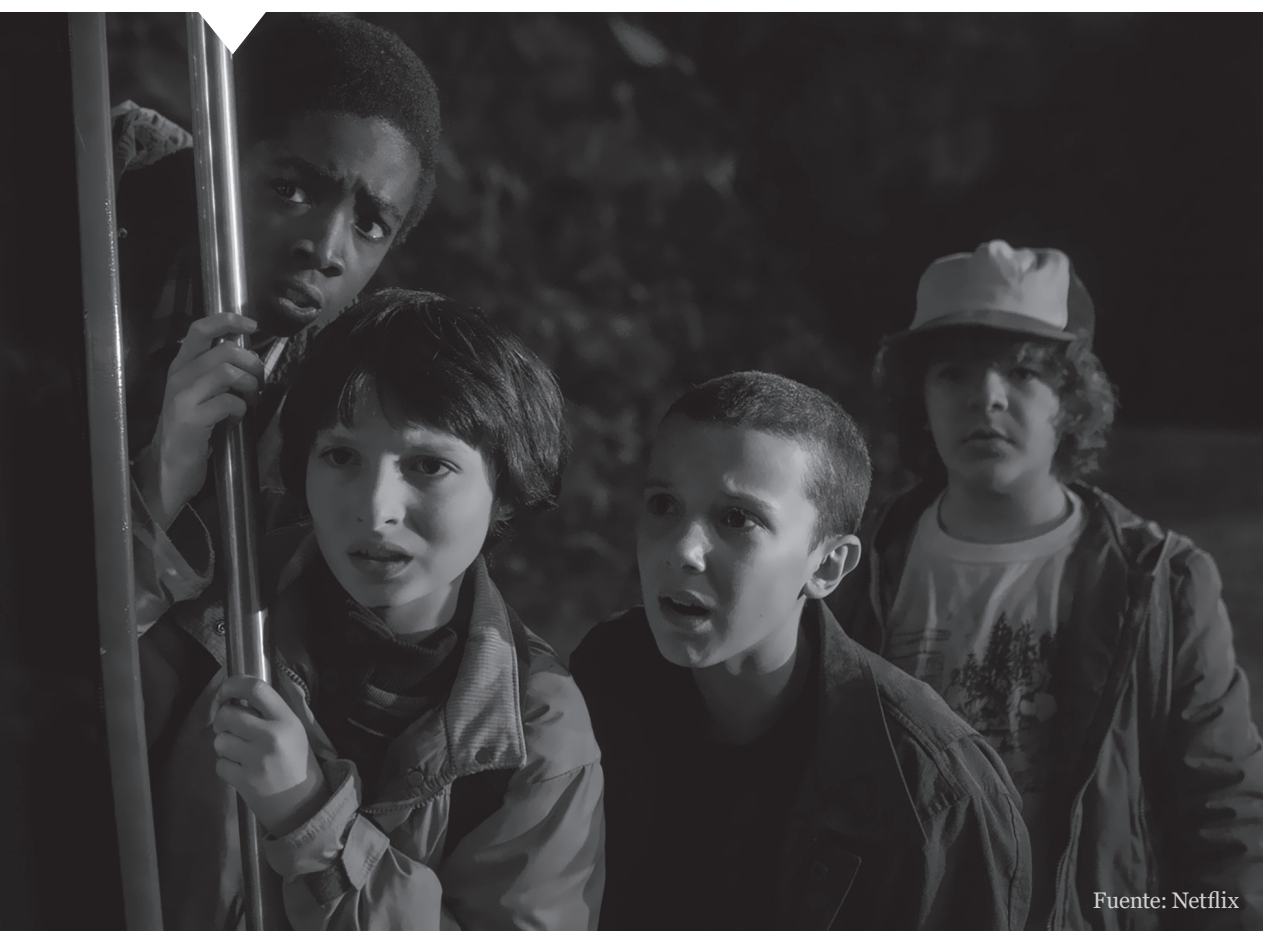

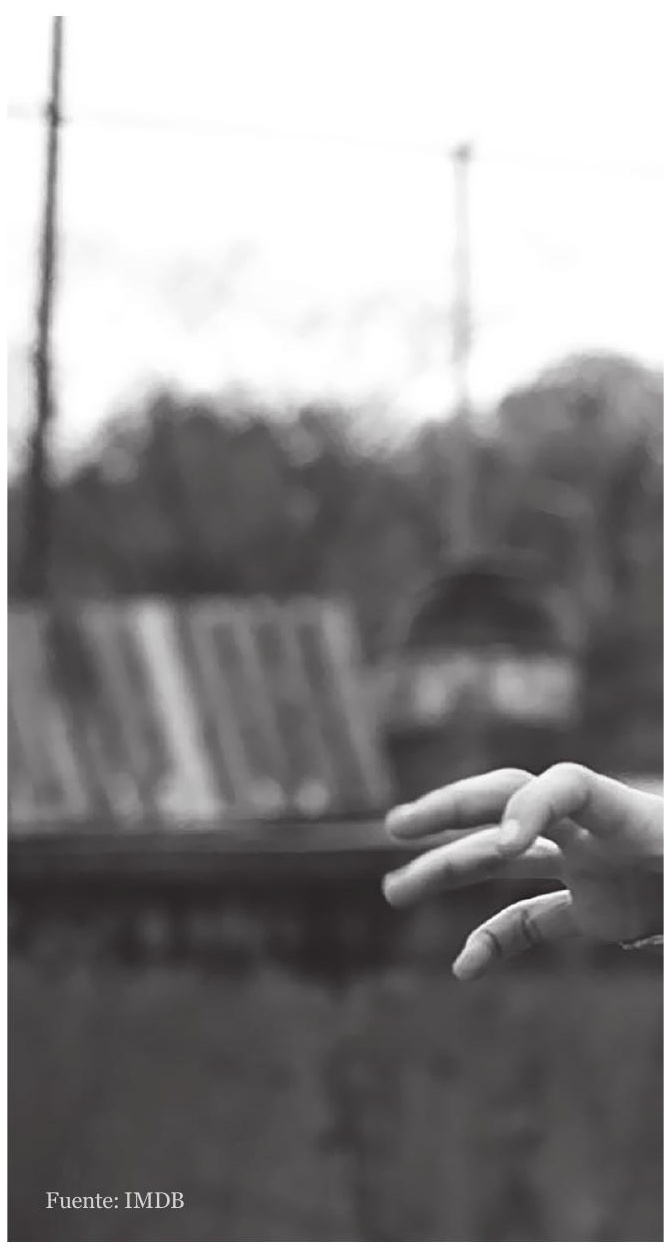

mido exclusivamente a través del streaming, lo cual nos advierte de una cuestión muy tangible en torno al usuario global y relacionada con toda la parafernalia tecnológica actual (smartphones, tablets, laptops, televisores inteligentes, entre otros artefactos); nos referimos a la aparición de un nuevo tipo de consumidor de entretenimiento. En ese sentido, se puede observar, a diferencia de los llamados televidentes, por ejemplo, una diversidad amplia de medios para acceder al contenido audiovisual y, ligado a esta cuestión, un dinamismo del público en relación con su propia elección de entretenimiento, más focalizada y personalizada, y con la respectiva disponibilidad de tiempo del usuario.

Si hablamos de un nuevo tipo de consumidor de entretenimiento, como el mencionado cliente de Netflix, no estamos vaticinando la extinción del televidente o del radioescucha, por citar dos casos, sino la aparición de una plataforma y de un 


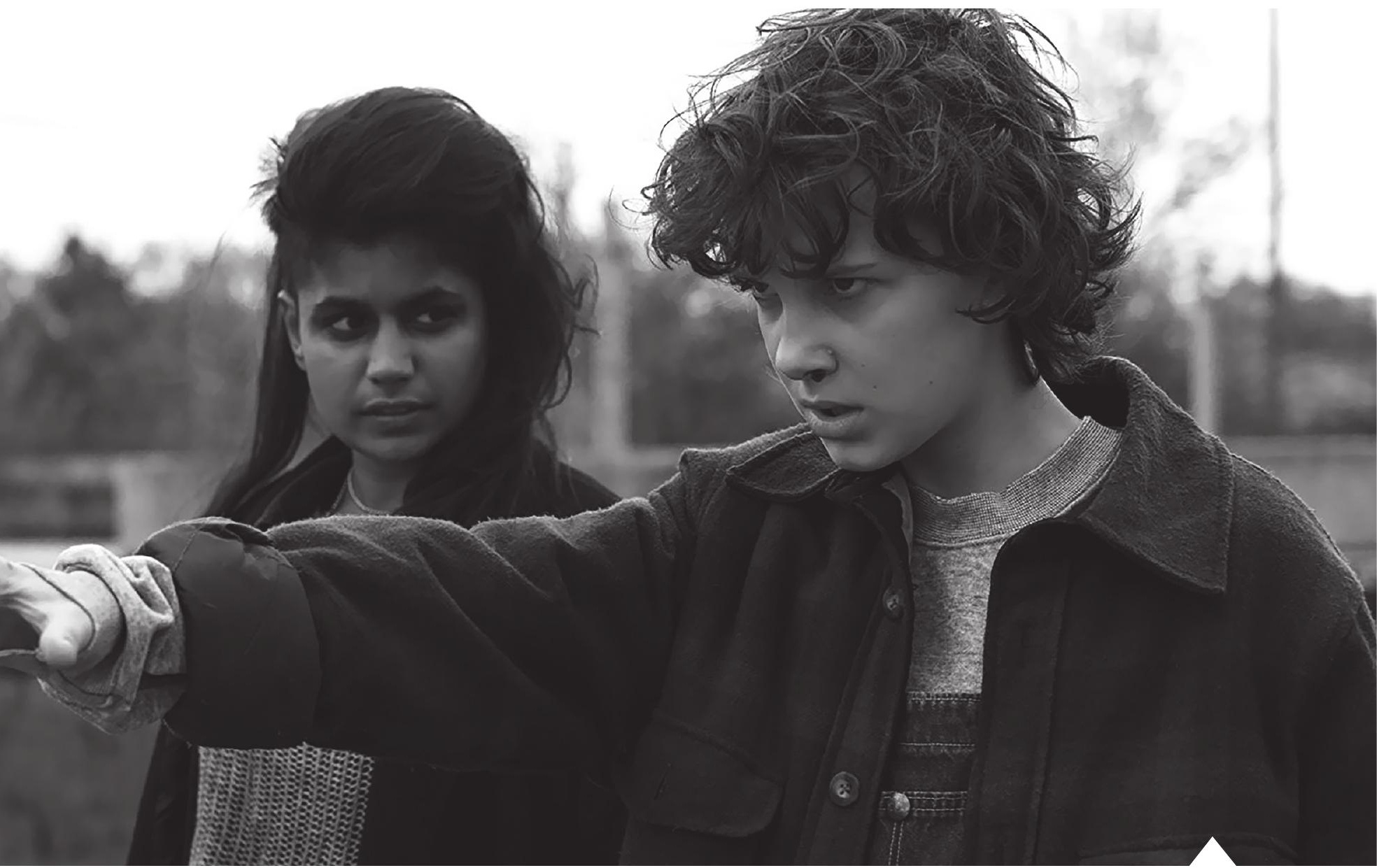

Eleven se enfrenta a una entidad siniestra y monstruosa como la del filme La Cosa de John Carpenter.

usuario íntimamente ligados a nuestra era digital. Generaciones anteriores a la actual generación del milenio (los millennials) fueron testigos de la aparición de distintas tecnologías, las cuales, en algunos casos, fueron utilizadas también como pasatiempo. La diferencia de los actuales consumidores millennials (o de los usuarios pertenecientes a otras generaciones que participan de este nuevo medio) con respecto a las otras formas y costumbres de acceso al entretenimiento radica en la hiperconectividad digital que las viejas tecnologías aún no permitían. En otras palabras, un consumidor millennial, al ser un usuario hiperconectado, puede generar interacciones inéditas, las cuales pueden llegar también a la creación misma de nuevo contenido. Esto nos hace pensar que el consumidor millennial, al ser receptor y emisor de contenido, está más abierto a entender y a apreciar un mensaje que quiera poner en evidencia un juego de intertextualidad explícita. Por ejemplo, algunas de las producciones cinematográficas de hoy apelan mucho a este abierto juego de intertextualidad; pensemos en una película como Ready Player One: comienza el juego (Ready Player One, 2018) de Steven Spielberg. En esta película, y me refiero a su público objetivo, se busca captar y satisfacer a ese consumidor millennial que puede disfrutar de una avalancha de referencias propias de la cultura pop, generando un diálogo donde la intertextualidad es utilizada como un elemento más bien decorativo ${ }^{3}$. Por otro lado, y aunado a lo que hemos mencionado, la intertextualidad cinematográfica puede operar también en producciones de streaming, y con eso apropiarse de parte del acervo temático e histórico del cine. Ese es el caso particular de la serie original de Netflix, Stranger Things, estrenada en el 2016 y creada por los hermanos Matt y Ross Duffer, quienes exploran el legado del cine de género de los ochenta como un elemento sustancial de su historia de aventuras y ciencia ficción.
Ahora, la relación entre el cine ochentero de género y Stranger Things no es de ocultamiento en torno a sus referencias cinematográficas, pues la serie plantea una exhibición de sus influencias fílmicas acorde no solamente a homenajes explícitos, sino también a la construcción de un argumento que retoma lo mejor de este género de aventuras y ciencia ficción. En otros términos, los hermanos Duffer recuperan con eficacia ideas y conceptos de producciones como E. T., el extraterrestre (E. T. the ExtraTerrestrial, 1982) de Steven Spielberg, La cosa (The Thing, 1982) de John Carpenter, o Cuenta conmigo (Stand by me, 1986) de Rob Reiner, para un público que puede comprender y apreciar una narración de fuerte carga intertextual, la cual, en este caso, revitaliza un cine y una estética a través de un nuevo medio digital como el streaming 4 . En ese sentido, Stranger Things se apodera de forma vigorosa de la tan mentada nostalgia ochentera, en su versión 
hollywoodense, al crear un producto cultural que encaja perfectamente con el sentir del usuario millennial y su capacidad de disponer de un gran abanico de información propia de la cultura pop de distintas épocas.

Si pensamos en la trama de Stranger Things, por dar un ejemplo, podemos observar el rescate y la reutilización de algunos recursos empleados por las películas mencionadas líneas arriba: de E. T., el recurso de introducir a un personaje que proviene de otro mundo o realidad desconocida (en el caso de la serie, el personaje de Eleven); de $L a$ cosa, la idea de tener que enfrentarse a un ser monstruoso y de origen siniestro (en la serie el ser monstruoso es el Demogorgon); de Cuenta conmigo, el planteamiento de la amistad de jóvenes adolescentes que se aventuran en una búsqueda que traza una historia de aprendizaje (en el caso de la serie la búsqueda se inicia con la desaparición del personaje Will Byers). Asimismo, uno de los mayores méritos de los hermanos Duffer es haber armonizado por lo menos estos tres elementos de tal manera que la historia narrada va aumentando su capacidad de atracción e interés, como toda buena narración de suspenso, resolviendo el problema de caer en el fácil recurso de las referencias pop hechas solamente para satisfacer al público. Además, y aludiendo al tema de la serie y su respectivo diálogo intertextual, hay que notar que los Duffer vuelven también a recuperar la tan conocida tesis de este tipo de cinematografía juvenil, nos referimos, a grandes rasgos, a la aceptación de la pérdida como parte de un ritual que da paso al crecimiento. Y es nuevamente el cine de Spielberg el que tiene un mayor peso en esta cuestión, sin olvidarnos nuevamente de Rob Reiner y su Cuenta conmigo, lo cual conecta a esta serie con otras propuestas similares como Super 8 (2011) de J. J. Abrahams, película producida por el propio Spielberg que toma la misma temática juvenil y similares referencias cinematográficas. Al parecer el mercado para una cinematografía juvenil de este tipo puede seguir generando demanda; el hecho es que, debido al éxito de Stranger Things, se estrenó una segunda temporada el año pasado y se planea estrenar un tercera en el 2019.
Hemos empezado considerando que parte del legado temático e histórico del cine ha encontrado también espacio en los nuevos soportes digitales como el streaming. El marco de una intertextualidad más o menos explícita nos ha llevado a observar cómo una serie de Netflix, Stranger Things, ha podido reavivar una cinematografía tan particular como la producida en el Hollywood de los años ochenta, apelando a un público global, hiperconectado y de raíz básicamente millennial. Público que ve en este tipo de producciones el cumplimiento de sus ansias generacionales de experimentar ese viejo suspenso juvenil, aunque sea fuera de las todavía existentes salas de cine.

1 Otro caso de un buen uso del 3D fue la película Hugo (2011) de Martin Scorsese, que puede ser considerada una carta de amor al cine por parte de uno de los directores más importantes de los últimos tiempos.

${ }^{2}$ Algunos ejemplos destacables de contenido original de Netflix, además de Stranger Things, son: House of Cards, Daredevil, The Crown, Narcos, 13 Reasons Why y Orange Is the New Black.

${ }^{3}$ Otras producciones actuales que utilizan muchas referencias a la cultura pop son películas como Deadpool (Tim Miller, 2016) y Deadpool 2 (David Leitch, 2018), las cuales proponen un diálogo intertextual como parte de una comedia que se sustenta, entre otros elementos, en la parodia y en romper la llamada "cuarta pared". En un tono más bajo, pero haciendo de las referencias pop parte de su comedia también, nos encontramos con Ted (2012) y Ted 2 (2015) de Seth MacFarlane.

${ }^{4}$ Otras películas de Spielberg que también participan en este diálogo intertextual, pero que aparecieron en los años setenta, son Tiburón (1975) y Encuentros cercanos del tercer tipo (1977). Por otra parte, también se pueden observar otras referencias filmicas que cumplen un papel más limitado y que se utilizan como parte de la recreación de la atmósfera o como guiños fugaces: Alien, el octavo pasajero (Ridley Scott, 1979), El resplandor (Stanley Kubrick, 1980), Poltergeist: juegos diabólicos (Tobe Hooper, 1982), Pesadilla en Elm Street (Wes Craven, 1984), Firestarter (Mark L. Lester, 1984), Los exploradores (Joe Dante, 1985), Commando (Mark L. Lester, 1985) y Los Goonies (Richard Donner, 1985). La lista puede extenderse a más elementos culturales del terror y la ciencia ficción de los ochenta, como los creados por el escritor Stephen King, cuyas ficciones han inspirado numerosas producciones cinematográficas, como Firestarter, Cuenta conmigo y El resplandor.

\section{Winona Forever}

\author{
Alessandra Sánchez-Pinto
}

Cher, Madonna, Adele, Winona. Pocas personas tienen el privilegio de no necesitar apellido. Winona, dependiendo de a quién se le pregunte su nombre, causa diferentes reacciones, desde "Ícono de los noventa" hasta "Ella es la que robaba ropa, ¿no?”. Efectivamente, Winona voló alto y cayó profundo, pero nunca despareció. Al visitar su página en Internet Movie Database (IMDb) me pude dar cuenta de que, al contrario de la impresión popular, Winona no desapareció sino que ha trabajado constantemente en películas a través de los años, como Una mirada a la oscuridad (A Scanner Darkly, Richard Linklater, 2006), El amor sucede (Stay Cool, Ted Smith [Michael Polish], 2009), Turks and Caicos (David Hare, 2014) y su notable participación como la prima ballerina Beth Macintyre en El cisne negro (Black Swan, 2010) de Darren Aronofsky. Sin embargo, en el 2016, con el estreno mundial de Stranger Things en Netflix, Winona asciende al nivel de popularidad global de su juventud.

Winona regresa en la serie de los hermanos Duffer que se caracteriza por su estilo ochentero y sus referencias a la época. Interpreta a Joyce Byers, una madre preocupada que busca desesperadamente a su hijo. Puedes sentir su angustia; su mirada transmite una ansiedad mortificante, representa el miedo más profundo, el terror a que la persona que amas con todo tu ser desaparezca sin dejar rastro. Su representación de Joyce Byers le ganó una nominación a los Golden Globes y otra a los Screen Actors Guild Awards, aunque, si bien no obtuvo los premios, las nominaciones le dieron meme status, por su cara de confundida durante el discurso de su coestrella 
David Harbour, lo que la volvió trending topic en Twitter y la hizo cool para la nueva generación. Y si algo es Winona Ryder, es cool. Los hermanos Duffer, creadores de la serie, hablaron de este fenómeno en una entrevista para el New York Times: "Winona-ness", un aire de fragilidad con una fuerte determinación. Fue ese factor "Winona-ness" el que convenció a los Duffer de que ella era la indicada, y no fueron los únicos; las reacciones de la audiencia con el regreso de Winona fueron masivas y positivas. Para los Duffer: "Son los 'Winona Forever' fans, hay demasiados. Ella es todo un ícono. Nosotros crecimos con sus películas. Estábamos anhelando que, si nosotros queríamos tan desesperadamente verla en pantalla, otras personas sintieran lo mismo".

Su personaje encaja a la perfección con su personalidad. Joyce Byers es una ex chica cool de secundaria que nació y creció en Hawkins, Indiana. Vale la pena destacar que Indiana parece ser el lugar de preferencia para eventos sobrenaturales y alienígenas; al parecer existe una promoción turística para seres interdimensionales de la cual no estamos enterados. Las personas desaparecen en el bosque, se reportan secuestros alienígenas, experimentos del gobierno, lavados de cerebro y múltiples cultos, todo en el remoto y "tranquilo" estado de Indiana. Joyce está determinada a encontrar a su hijo y no le importa si el resto del mundo piensa que está loca porque ha pegado luces de Navidad en su sala, ella está convencida de que su hijo se está comunicando a través de las luces y lo va a encontrar. En una entrevista con el New York Times (Rochlin, 2016), Winona declaró sobre cómo se conectó con el personaje de Joyce gracias a la ayuda de su madre: No tengo hijos, así que mi madre me ayudó mucho en esto. Yo la llamaba a veces y decía: "Mamá, ¿qué harías si todo indica que tu hijo está muerto, pero crees que las luces te dicen que no lo está?” Y ella me dijo: "Cariño, lo creería totalmente. Es natural”.

Como Joyce Byers, Winona regresa al ojo público, pero no significa que haya desaparecido antes de lle- gar a Netflix. Al contrario, ha trabajado casi todos los años sin falta; la diferencia es que ella no acepta cualquier rol por el hecho de trabajar. Bien lo dice Daniel Waters, el escritor del guion de Los brezos salvajes (Heathers, Michael Lehmann, 1988) y amigo de Winona: "Ella no va a sacar un periscopio y buscar trabajo, ella solo espera hasta que el trabajo aparece. Creo que ella es la última conexión con el Hollywood antiguo. Tiene ese glamur que está perdido hoy en día, que ha sido golpeado por Instagram y TMZ. Ella inspira ese amor cultista que ya no veo a otros ingénues inspirar. Audrey Hepburn solía mandarle ropa”.

Winona no tiene una cuenta oficial de Instagram ni de Twitter; un requisito para cualquier otra persona de su rubro. Para ella no es necesario publicar su vida para tener presencia en los medios o para no sentirse "olvidada"; los fans lo dejan claro, tiene un cult following enorme y se lo ha ganado.

Como dice Noel Murray (2016) en la revista Rolling Stone: "Ella representó un punto de vista completo, le dio voz a los adolescentes que disfrutaban de la literatura y la música alternativa, que querían hacer una diferencia en el mundo. $\mathrm{Y}$ en este show, ella aún defiende a los incomprendidos".

Es verdad, ella se ubicaba en el otro lado del espectro, no era la estrellita rosa y llena de glitter, era dark. No es extraño que se volviera la heroína de los raros y desadaptados, esa era su bandera, toda su vida se sintió fuera de lugar. Cuando tenía 10 años, su familia se mudó a Petaluma, California y, en su primera semana en Kenilworth Junior High, unos chicos que la confundieron con un niño afeminado, la molieron a patadas. "Estaba usando un viejo traje de un Salvation Army. Cuando estaba entrando al baño escuché a un grupo de gente decir 'Hey, marica'. Golpearon mi cabeza contra un locker. Caí al piso y me sacaron la mierda a patadas. Me tuvieron que poner puntos".

Desde entonces tuvo clases en casa por el resto del ciclo. No fue sino hasta que su ingreso a la secundaria y su rol como Lydia en Beetlejuice (1988) de Tim Burton coincidieron, que Winona pensó en tener una experiencia escolar diferente.

El filme la presentó al público masivo como una chica gótica y rara. La película fue un éxito, pero ni siquiera eso la salvó de los bullies en secundaria. "Recuerdo pensar 'Ohh es Beetlejuice, la película número uno del momento, esto va a hacer que las cosas sean geniales en el colegio', pero solo lo volvió peor. Me llamaban bruja”. Sin embargo, esta historia tiene un final feliz, uno que rivaliza con $L a$ venganza de los nerds (Revenge of the Nerds, Jeff Kanew, 1984). "Años después fui a una cafetería y me encontré con una de las chicas que me había pateado en el colegio. Ella me dijo: 'Winona, Winona, ¿me pue-

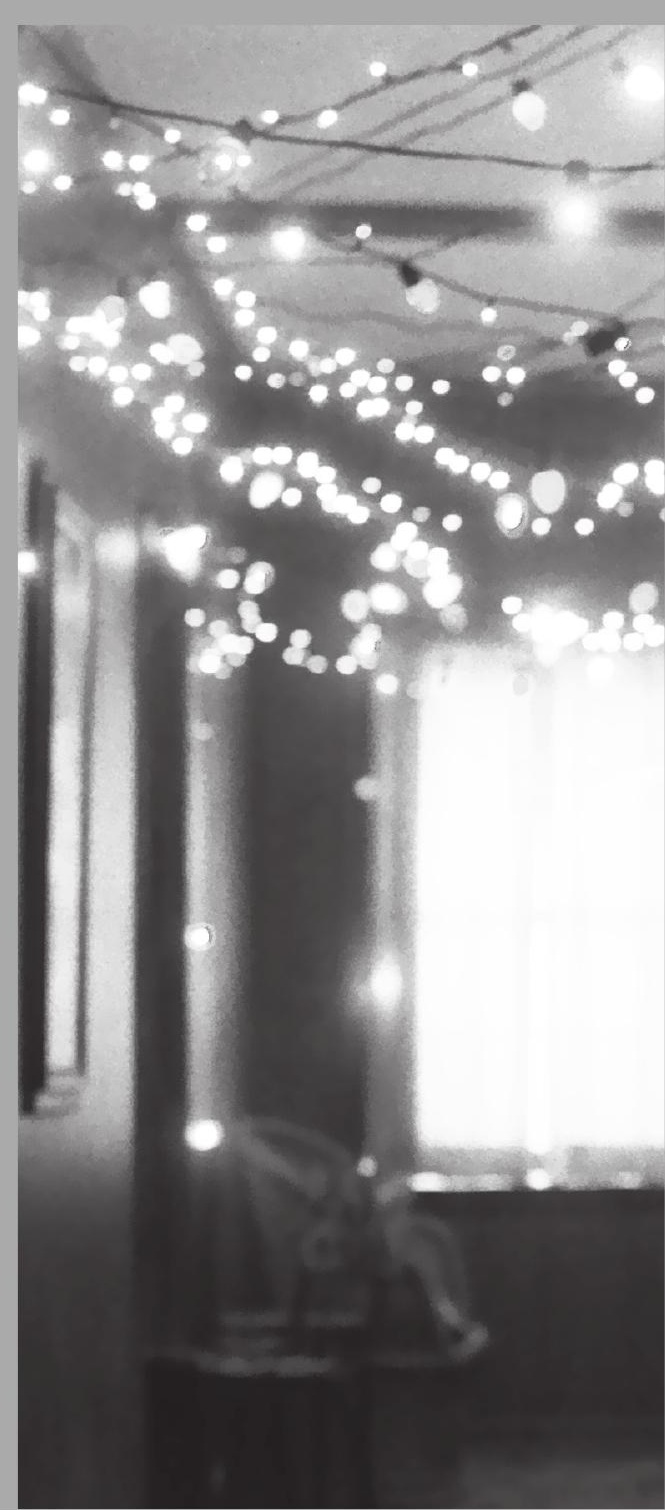


des dar tu autógrafo?’. Le dije: ‘¿Me recuerdas? Recuerdas en sétimo año cuando golpeaste a un chico?'. 'Eso creo', me respondió, y yo le dije: 'Esa era yo. Vete al carajo"”.

La graduación de Winona como profesional llegó con su papel en $E l$ cisne negro, como ella lo dice: "Pasé de ser una adolescente rara a ser una chica pixie a ser alguien con quien no sabían qué diablos hacer". No fue sino hasta el 2010, con su cameo en la película de Darren Aronofsky como una acabada prima ballerina, que encontró un diferente rol dramático como profesional. "Sentí que era la primera vez en un largo tiempo en que las personas realmente respondieron a mí. [...] Fue algo liberador porque estaba interpretando a alguien de mi edad. En mi mente, y creo que en la mente de otras personas también, eso ayudó bastante. Sentí que me gradué”.

Al encontrarse otra vez en Hollywood después de su graduación, se volvió a juntar con Tim Burton para el videoclip "Here with me" de la banda The Killers; prestó su voz en Frankenweenie (2012), del mismo Burton, y en el 2015 el diseñador Marc Jacobs la volvió la cara de su marca, 14 años después del escándalo en que Winona roba una chompa del diseñador en Saks Fifth Avenue. Después del éxito de Stranger Things, las múltiples campañas de moda y los grandes roles que la persiguen, podemos estar seguros de que Winona fue, es y será cool.

\section{Referencias}

Murray, N. (2016). Why we missed Winona Ryder and How Stranger Things brought her back. Rolling Stone Magazine. Recuperado de: https://www.rollingstone.com/tv/tv-news/ why-weve-missed-winona-ryder-and-howstranger-things-brought-her-back-94678/

Niven, L. (2016). Why Winona Ryder Is de: https://www.vogue.co.uk/article/winonaryder-is-back

Rochlin, M. (2016). Winona Ryder, an Emblem of ' 90 s Cool, Grows Up. The New York Times. Recuperado de: https://www. nytimes.com/2016/07/17/arts/television/winona-ryder-an-emblem-of-90s-cool-growsup.html

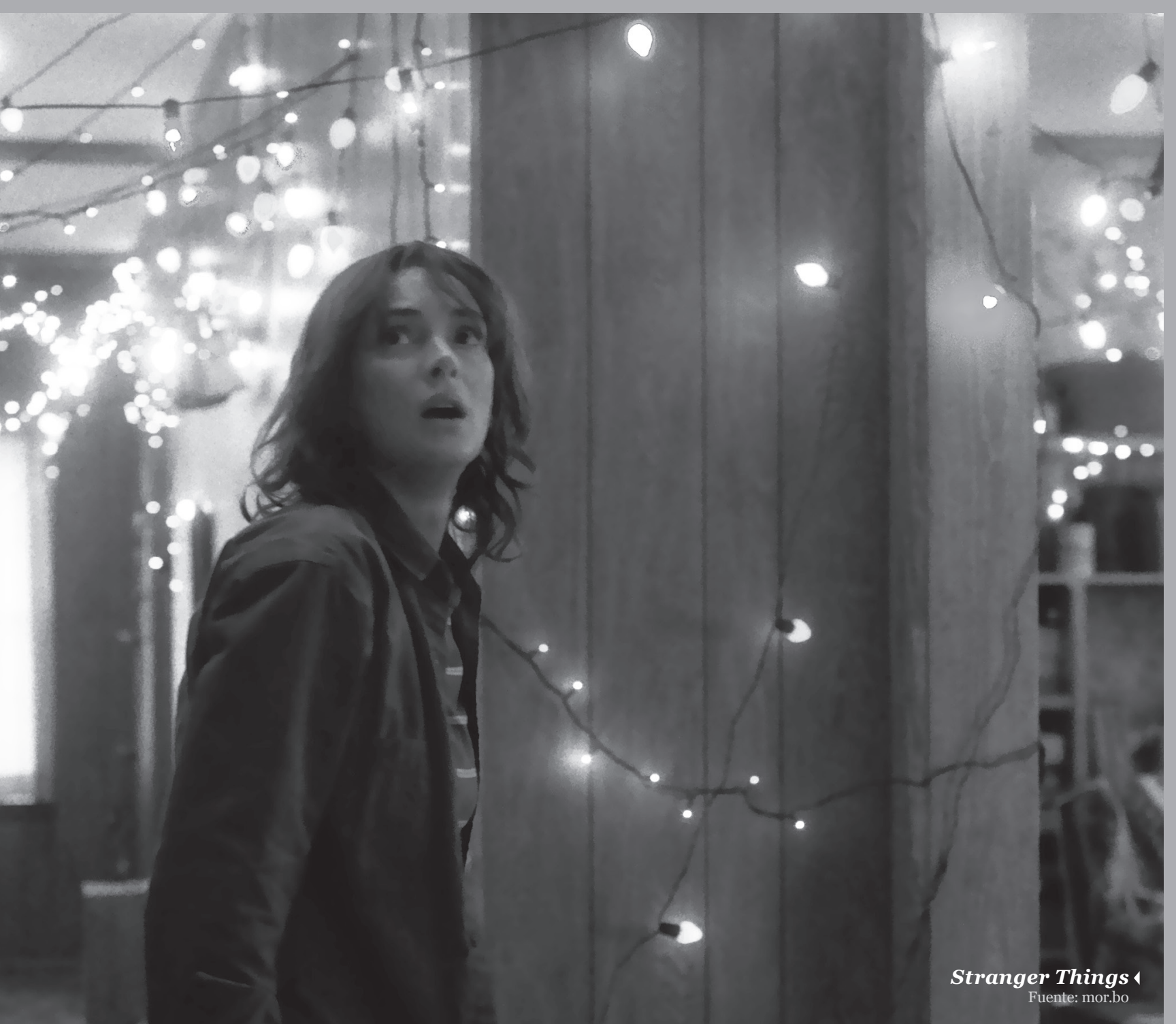

